\title{
Long-run regional population disparities in Europe during modern economic growth: a case study of Spain
}

\author{
María Isabel Ayuda • Fernando Collantes • \\ Vicente Pinilla
}

Published online: 3 April 2009

(C) Springer-Verlag 2009

\section{Erratum to: Ann Reg Sci \\ DOI 10.1007/s00168-008-0260-9}

In Table 1 of the article, doi:10.1007/s00168-008-0260-9, all of the commas (,) were mistaken by dots (.). The fault lies solely on the authors.

Below we reproduce the correct version of this table.

The online version of the original article can be found under doi:10.1007/s00168-008-0260-9.

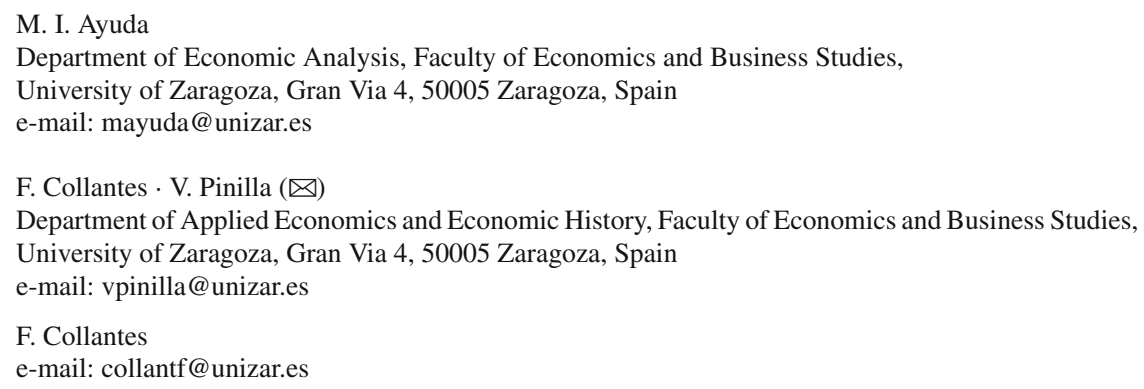


Table 1 Summary statistics of the administrative units

\begin{tabular}{|c|c|c|c|c|c|}
\hline & \multicolumn{5}{|c|}{ Administrative units $\left(\mathrm{km}^{2}\right)$} \\
\hline & \multirow[t]{2}{*}{$n$} & \multicolumn{4}{|l|}{ Area } \\
\hline & & Mean & $\mathrm{SD}$ & Max & Min \\
\hline Belgium & 9 & 3,391 & 613 & 4,441 & 2,422 \\
\hline France & 88 & 6,261 & 1,346 & 10,726 & 2,859 \\
\hline Italy & 95 & 3,153 & 1,608 & 7,520 & 882 \\
\hline Portugal & 19 & 4,850 & 2,432 & 10,871 & 815 \\
\hline Spain & 48 & 10,359 & 4,702 & 21,657 & 1,986 \\
\hline Sweden & 24 & 18,302 & 23,468 & 105,493 & 3,038 \\
\hline Switzerland & 24 & 1,721 & 2,002 & 7,114 & 173 \\
\hline The Netherlands & 12 & 3,461 & 1,312 & 5,741 & 1,434 \\
\hline United Kingdom & 87 & 2,624 & 2,043 & 10,907 & 123 \\
\hline
\end{tabular}

Source: see Appendix 1

$n$ number, $S D$ standard deviation, Max area of the largest administrative unit, Min area of the smallest administrative unit 